\title{
El "bullying" y otras formas de violencia adolescente.
}

Bullying an other forms of adolescent violence.

\author{
A. Gómez', FJ. Gala², M. Lupiani' ${ }^{3}$ A. Bernalte ${ }^{4}$, MT. Miret $^{5}$, S. Lupiani ${ }^{5}$ \\ y MC. Barreto5
}

\section{RESUMEN}

En este artículo, tratamos de analizar la violencia adolescente centrándonos principalmente en la que se produce en el ámbito escolar. En primer lugar, hemos precisado los conceptos de agresividad, violencia, bullying y otros relacionados. A continuación, revisamos y comparamos algunas de las investigaciones más destacadas acerca de la incidencia del bullying; para luego reflexionar sobre las causas y circunstancias que elicitan y mantienen estas conductas. Por último, sugerimos algunas líneas de actuación desde distintas instancias sociales que se encaminen hacia su prevención.

Palabras clave: Bullying; Violencia juvenil; Adolescencia.

Cuad Med Forense 2005; 13(48-49):165-177

\section{ABSTRACT}

In this article, we try to analyze adolescent violence, focusing mainly on the school environment. In the first place, we have determined the concepts of aggressiveness, violence, bullying and other related topics. Next, we have reviewed and compared some of the most outstanding research concerning the incidence and prevalence of bullying. Then we reflect upon the causes and circumstances that elicit and sustain these kinds of behavior. Finally, we suggest some means of action from different social organizations that work toward prevention.

Key words: Bullying; Youth violence; Adolescence.

Correspondencia: Prof. Dr. Antonio Gómez Sanabria. Facultad de CC de la Educación (UCA). Avda. República Saharaui s/n. 11519 Puerto Real. (Cádiz). E-mail: antonio.sanabria @uca.es.

1 Profesor Asociado de Psicología Social (UCA).

2 Catedrático de Ciencias Psicosociales Aplicadas a la Salud (UCA).

3 Profesora Titular de Enfermería Médica (UCA).

4 Profesor Titular de Antropología de la Salud (UCA).

5 Investigadores del Grupo. 


\section{I.- INTRODUCCIÓN:}

Las personas recurrimos en numerosas ocasiones a la violencia y a la agresión para dominar a otros semejantes o para tratar de gestionar nuestros conflictos. Pero es un lugar común en nuestro marco cultural entender que las conductas violentas y agresivas no forman parte de una estrategia adecuada para la convivencia ni para la buena gestión de los conflictos interpersonales o intergrupales. Podemos argumentar, entre otras cosas, que, si bien inicialmente las agresiones pueden conllevar la represión del conflicto manifiesto, al asentarse esta pseudogestión en la desigualdad de poder, sobrevive el conflicto latente a la espera de mejor ocasión para que reaparezca el conflicto manifiesto y, a partir de aquí, o bien recomponer las relaciones en el marco contrario, en el que los roles de "dominado - dominador" estén intercambiados, o recomponerlas en un escenario vivenciado como más equitativo, sin el uso de ese tipo de conductas. Como podemos entender, lo que conduce a una adecuada gestión de los conflictos es el uso de formas no violentas de relación. Existe, pues, una contradicción entre las conductas deseables y las frecuentes.

Nuestra sociedad parece sensibilizada hacia la violencia en algunas de sus manifestaciones, como la violencia juvenil, la violencia de género, etc.. En concreto, en las dos últimas décadas, los medios de comunicación han destacado las noticias relacionadas con la violencia adolescente y juvenil y, específicamente, con la que se produce en el ámbito escolar o derivada de ella.

En este artículo, una vez que hayamos delimitado los conceptos y la incidencia de estas conductas de violencia adolescente en nuestro entorno, vamos a tratar de reflexionar sobre las causas y circunstancias que las elicitan y mantienen, para, después, sugerir algunas líneas de actuación desde distintas instancias sociales que se encaminen hacia su prevención.

\section{2.- ASPECTOS CONCEPTUALES:}

En el nivel coloquial del lenguaje, el concepto de violencia se utiliza comúnmente como sinónimo de agresividad. Pero en el nivel científico, aunque no todos los autores coinciden, se suele reservar el término agresividad para referirse a tendencias impulsivas derivadas de un sentimiento de frustración o insatisfacción y, los términos agresión y violencia, se utilizan para significar una conducta a cuya actualización se dirigen esas tendencias impulsivas ("se ha cometido una agresión", "se ha hecho violencia"). En esta línea, el diccionario de la Real Academia de la Lengua, en su edición de 200 I [I], define a la agresividad como "tendencia" y a la agresión y violencia como "acto" y "acción" respectivamente. Por último, los adjetivos derivados (agresivo/a, violento/a) se refieren tanto a una característica de personalidad de los sujetos ("Juan es muy agresivo o es violento") como a la cualidad de una conducta o de un suceso ("le hizo un gesto agresivo"o "le dijo palabras agresivas").

Pero, si los términos agresión y violencia se refieren ambos a conductas que en muchas ocasiones derivan de una tendencia impulsiva y que causan un daño o perjuicio a un tercero, ise diferencian en algo? y en caso afirmativo, ien qué?: Cuando en un partido de fútbol, un jugador le da una patada a otro intencionadamente solemos decir que le ha agredido $y$, del receptor, que ha sufrido una agresión. Si al terminar el encuentro en el que su equipo ha perdido, los "ultras" preparan una algarada, destruyen el mobiliario urbano, insultan y agraden al árbitro o a los partidarios del equipo contrario o se enfrentan a la policía, hablamos de violencia en el deporte.

Aquí tenemos algunas diferencias que nos pueden ayudar a delimitar los conceptos: en el primer caso, los jugadores están en un contexto normativo (las reglas del juego) que incumplen pero se someten a una autoridad (la del árbitro). En el segundo caso, los ultras no se someten a ningún contexto normativo ni a la autoridad. En el primero, los autores están en una situación que podríamos 
decir de igualdad, de uno a uno, no hay un abuso de poder y se está a la vista de todos. En el segundo, se arropa cada uno en el anonimato para utilizar abusiva e injustamente el poder del grupo.

Veamos otro ejemplo: si durante el recreo, en el colegio, un alumno tiene un balón que no quiere devolver a su dueño y éste se lo quita de un empujón porque se tiene que ir a clase, el dueño del balón está resolviendo un conflicto por medio de una conducta agresiva, pero no podríamos calificarla de violenta porque la intención del agresor no es hacerle un daño físico ni psicosocial gratuito al otro, sino utilizar un recurso inadecuado para un objetivo razonable.

En el origen de las conductas agresivas existe siempre un conflicto que, en definición de Suárez [2], es "un proceso interaccional... que se construye recíprocamente entre dos o más partes... en el que predominan las interacciones antagónicas sobre las competitivas. Algunas veces el antagonismo lleva a la agresión mutua, donde las personas que intervienen lo hacen con sus pensamientos, afectos y discursos". Así el conflicto es un proceso que se origina en una diferencia de intereses y las conductas agresivas son una forma de resolver esa diferencia de intereses.

La violencia va más allá de ser una forma agresiva de solucionar un conflicto. En primer lugar, para ejercer violencia no es necesario que exista un conflicto previo entre las partes; incluso, puede que antes no se conociesen, puede ser una violencia con un objetivo lúdico, con la que únicamente pretenden los actores divertirse. En segundo lugar, suele ser unidireccional y conllevar una relación desequilibrada entre las partes, en la que las fuerzas son desiguales entre el actor y la víctima, a favor del actor; frecuentemente es un grupo contra una víctima aislada o un agresor más fuerte respaldado por un grupo que le aplaude la acción. Conlleva, además, una intencionalidad de hacer daño gratuito a la víctima en ausencia de una regulación normativa de la interacción. Ortega y Mora-Merchán [3] definen la violencia interpersonal como "el ejercicio agresivo físico, psicológico, social o verbal mediante el cual una persona o grupo de personas actúa, o estimula la actuación de otros, contra otra persona o grupo, valiéndose de ventajas sociales que le proporcionan su situación física, psicológica o social".

La violencia interpersonal o intergrupal se pueden dar en cualquier contexto interactivo en el que intervengan seres humanos, como individuos o como grupos. Así, los ámbitos familiar, escolar, laboral, lúdico, deportivo o institucional son marcos psicosociales en los que pueden surgir estas conductas. Los actores y receptores de este tipo de conductas pueden ser de cualquier edad y género.

La violencia puede llevarse a cabo de diversas maneras, como acabamos de ver en la anterior definición, puede ejercerse a través de golpes u otras conductas físicas que hagan daño; por medio de influencia psicológica, aterrorizando o manipulando de forma negativa sus sentimientos; ejercitando o propiciando el aislamiento o el rechazo social de la víctima; o a través de amenazas o insultos directos o conductas verbales dirigidas a terceras personas que comporten acusaciones falsas y/o difamaciones sobre la víctima.

Estas formas de manifestación de la violencia dan lugar a su clasificación en violencia física y verbal, directa e indirecta, incluso activa o pasiva (puede ejercerse una violencia que consista en no prestar una ayuda necesaria a una persona a sabiendas del daño que se le hace y queriendo ese daño). Pero, existen algunas manifestaciones a las que, por sus peculiares características, se les da una denominación particular: mobbing, violencia de género, acoso sexual, violencia doméstica, bullying, acoso psicológico, etc. Y, de igual modo, también existen algunos delitos más extendidos entre la juventud -a los que se les presta mayor atención- como son el tráfico de drogas y sus derivados: asesinatos o lesiones por ajustes de cuentas, robos, asociaciones para delinquir, etc. 
Una de las formas de violencia/delito que más repercusión está teniendo actualmente sobre las personas en edad escolar es el bullying. Se trata de un anglicismo que se podría traducir como "matonismo" (bully significa matón y, to bully, significa intimidar con gritos y amenazas y maltratar a los débiles). Oñate y Piñuel [4], entienden que el bullying se refiere sólo al maltrato físico y que éste constituye sólo una parte del total de conductas de hostigamiento y acoso que sufren los escolares, por eso prefieren usar el término mobbing, normalmente reservado para el acoso laboral, pero lo traducen en este ámbito como acoso escolar y lo definen como "un continuado y deliberado maltrato verbal y modal que recibe un niño por parte de otro $u$ otros, que se comportan con él cruelmente con el objeto de someterlo, apocarlo, asustarlo, amenazarlo y que atentan contra la dignidad del niño". De hecho, no son pocos los autores que incluyen al bullying dentro de campo semántico del Acoso [5, 6, 7].

Por su parte, Díaz-Aguado [8] considera el bullying como una forma de violencia entre iguales que tiene las siguientes características: "I) suele incluir conductas de diversa naturaleza (burlas, amenazas, intimidaciones, agresiones físicas, aislamiento sistemático, insultos); 2) tiende a originar problemas que se repiten y prolongan durante cierto tiempo; 3) supone un abuso de poder, al estar provocada por un alumno (el matón), apoyado generalmente en un grupo, contra una víctima que se encuentra indefensa y que no puede por sí misma salir de esta situación; 4) y se mantiene debido a la ignorancia o pasividad de las personas que rodean a los agresores y a las víctimas sin intervenir directamente".

Ortega y Mora-Merchán [9] recogen una muestra importante de definiciones y ellos mismos lo definen como "una situación social en la que uno o varios escolares toman como objeto de su actuación injustamente agresiva a otro/a compañero/a y lo someten, por tiempo prolongado a agresiones físicas, burlas, hostigamiento, amenaza, aislamiento social o exclusión social aprovechándose de su inseguridad, miedo o dificultades personales para pedir ayuda o defenderse". En general, los distintos investigadores sobre el tema conceptualizan el bullying de forma semejante a ésta.

En los últimos años los medios de comunicación se han mostrado más sensibles a la violencia, tanto en la familia (de género, sobretodo), como a la que se produce en el medio escolar (bien entre adultos - padres a profesores-, bien entre alumnos -bullyng-) sin embargo, el tratamiento inadecuado de estos sucesos y la mala difusión mediática puede dar lugar a un desenfoque del problema en dos direcciones: $1^{\circ}$ ) Favorecer una "normalización" o habituación, con el consiguiente desinterés o conformismo y, $2^{\circ}$ ) Encauzar a la población hacia una "generalización o trivialización" del problema, de modo que a cualquier conflicto entre escolares se le asigne esta etiqueta. Para no sufrir este último error nos interesa analizar los casos concretos a la luz de unos criterios diagnósticos, que, siguiendo a Oñate y Piñuel [10] podemos resumir en tres: I) La existencia de una o más conductas de hostigamiento intencionadamente reconocidas como tales; 2) la repetición de la conducta que ha de ser evaluada por quien la padece como no meramente incidental, sino como parte de algo que le espera sistemáticamente, en el entorno escolar, en la relación con aquellos que le acosan; y, 3) la duración en el tiempo, con el establecimiento de un proceso que va a ir minando la resistencia del niño y afectando significativamente a todos los órdenes de su vida (académico, afectivo, emocional, familiar).

\section{3.- INCIDENCIA DE ESTAS CONDUCTAS:}

Ante el mencionado eco en los medios, tanto acerca del fenómeno del bullying como de la violencia juvenil en general, que, como hemos dicho, puede llevarnos a una percepción distorsionada del fenómeno, vamos a revisar los datos que aportan diferentes investigaciones sobre su 
presencia en nuestra sociedad; pero, no podemos olvidar que este fenómeno permanece en gran parte oculto -según el fenómeno de "punta de iceberg" tan conocido por la epidemiología, en virtud del cual, lo que se reconoce o denuncia no es más que un pálido reflejo de la realidad, permaneciendo el resto oculto como sucede en un iceberg- por lo tanto, los datos aportados por los distintos estudios los debemos considerar como una aproximación a la realidad.

Por otro lado, aunque hay estudios descriptivos longitudinales y transversales y estudios comparativos entre la situación anterior y posterior a la puesta en práctica de algún programa preventivo, nos faltan datos sobre momentos diferentes y suficientemente distantes entre sí para establecer comparaciones de su evolución a largo plazo. Los primeros estudios sobre bullying aparecen en los años 70 del siglo pasado (en Suecia, los realiza Olweus en 1973 y, en Gran Bretaña, Lowenstein en 1978 [ I I]), pero será en las décadas de los ochenta y los noventa cuando haya un incremento de los estudios sobre este problema. Su aparición en Noruega se debió precisamente al impacto mediático del suicidio de dos adolescentes en el plazo de una semana; D. Olweus, en 1985, a través del estudio más amplio que se ha realizado hasta el momento (I30.000 alumnos noruegos entre 8 y 16 años) concluyó que en torno al I5\% estaba implicado en conductas de este tipo (el $9 \%$ como agresores); las cifras que se concluyen en los diferentes estudios posteriores realizados por este autor en Suecia y en Noruega indican que entre el 13 y el $18 \%$ de los alumnos y alumnas están directamente implicados bien sea como agresores o como víctimas. A éstos hay que añadirle un pequeño porcentaje (entre el $1 \%$ y el $2 \%$ ) de alumnos y alumnas que son a la vez agresores y víctimas. Los estudios realizados en otros países europeos, norteamericanos y del resto del mundo marcan unas cifras y circunstancias relativamente parecidas que oscilan, en general, entre el $3 \%$ y el I $5 \%$ de agresores con frecuencia de al menos una vez por semana, y víctimas de una vez por semana entre el 2 y el $10 \%$. Algunas investigaciones ofrecen porcentajes más altos: Slee [12] en Australia concluye que un 23,8\% de alumnos de primaria sufren agresiones en el recreo al menos una vez por semana; Pereira y Mendoza [13] en Portugal, en 1996, hablan de un 16\% de agresores y un $21 \%$ de víctimas en secundaria; por su parte, Fonzi y Genta en 1999 [1 4], en Italia, encuentran que un $17,5 \%$ son víctimas, al menos una vez por semana, en primaria, cifra que desciende al 9,5\% en secundaria.

Pero en este fenómeno también está implicado otro gran número de estudiantes en papeles de colaboradores del agresor, animadores, contempladores pasivos de la agresión y defensores de la víctima. Papeles, los tres primeros, que son necesarios para el mantenimiento de las conductas violentas, en tanto reportan una recompensa social para el agresor y un incremento de la violencia soportada por la víctima.

Las investigaciones en España llegan a resultados similares a los expuestos. El primer estudio fue realizado en Madrid en 1989 por Fernández y Quevedo y después se han realizado otros como los de Cerezo y Esteban en Murcia [15], los de Ortega y Mora-Merchán desde 1993 en Sevilla -ya citados-, las investigaciones de Díaz- Aguado, Martínez- Arias y Martín- Seoane en Madrid [16]; el "Informe Cisneros VII sobre Violencia y acoso escolar en alumnos de Primaria, ESO y Bachiller" de Oñate y Piñuel (también citado) realizado, de igual modo, en Madrid. Por su parte, el Consejo Escolar de Andalucía ha publicado en el pasado año 2006 [17] datos sobre la percepción de la convivencia en los centros educativos. La investigación más completa realizada hasta la fecha en España es la presentada por Oñate y Piñuel en el Informe Cisneros X [18]. Para realizar esta investigación pasaron el cuestionario AVE -cuestionario de Autoevaluación de la Violencia Escolar[19] a 24.990 alumnos entre 7 y 18 años pertenecientes a 14 comunidades autónomas. Los resultados de estos estudios varían en función de los criterios utilizados. Por ejemplo, Ortega y Mora- 
Merchán [20] hablan del 19,4\% de agresores, pero reducen esa cifra al I,4\% al utilizar como criterio el haber cometido agresiones al menos una vez por semana durante el último trimestre. En general, las cifras de agresores oscilan entre el I I,4\% (Cerezo y Esteban) y 22,4\% (Oñate y Piñuel, Cisneros VII); las de víctimas están entre un 3,4\% (Díaz-Aguado) y un 23,3\% (Oñate y Piñuel, Cisneros X); las de personas ajenas, entre el 22,4\% (Ortega y Mora-Merchán) y 80,5 \% (DíazAguado); $y$, las ambivalentes, entre el 3,4\% (Díaz-Aguado) y el 43,8\% (Ortega). En la ya mencionada Encuesta del Consejo Escolar de Andalucía, y en lo referente a la provincia de Cádiz, a la pregunta de "con qué frecuencia se producen en tu centro las siguientes actuaciones del alumnado con relación a tus compañeros", de un total de 130 alumnos de ESO, Bachillerato y FP contestan que suceden "muchas veces"o "siempre" intimidaciones con amenazas, 16; agresiones verbales, 55; rechazos, 19; discriminaciones, 8; y daños en materiales de otros o del centro, 29.

Como podemos observar de forma general, la incidencia del problema del bullying es relativamente similar en los distintos países desarrollados y afecta directamente a la mitad de la población escolar. Pero este fenómeno no es uniforme a lo largo de la escolarización y tiene manifestaciones particulares al introducir algunas variables. En general, los estudios llegan a las siguientes conclusiones parecidas:

a) Se produce una progresiva disminución del número de agresores y víctimas entre primaria y secundaria (por ejemplo, en el Informe Cisneros VII, los autores hablan de que la tasa de acoso en siete veces superior en $2^{\circ}$ de Primaria respecto a $2^{\circ}$ de Bachillerato, pasando del $43 \%$ al $6 \%$ ).

b) Suele haber más agresores y más victimas entre los varones.

c) Éstos son agredidos sólo por varones, mientras que las chicas son agredidas tanto por chicas cuanto por varones.

d) Las chicas reciben más agresiones verbales y sociales que los chicos, quienes, por su parte, reciben más agresiones físicas.

e) Los alumnos con alguna diferencia significativa (física o psicológica) que les lleve a ser considerados inferiores en algún sentido son más proclives a ser víctimas.

f) Muchos alumnos que, en las primeras etapas escolares eran agresores, dejan de serlo en cursos más avanzados; pero los agresores de los cursos avanzados lo han sido también en los cursos anteriores. Es decir, no suelen incorporarse nuevos agresores en los últimos cursos.

La violencia entre iguales no es exclusiva del entorno escolar y, aunque los alumnos contestan que suelen darse estas conductas prioritariamente en los recreos, también se extienden a la calle donde adquieren formas más variadas de manifestación como pueden ser el consumo excesivo de alcohol, incluso a edades precoces en el marco del fenómeno conocido como "botellón"; la delincuencia común, sobre todo la relacionada con el tráfico de drogas y la obtención ilícita de recursos para conseguirlas; la violencia de género, que incluiría tanto agresiones sexuales y violaciones como las lesiones y crímenes pasionales; la violencia xenófoba y tribal (tribus urbanas -algunas conformadas por jóvenes de etnias o de países generadores de inmigración, en los países de acogida, como los célebres "Latin Kings"; fenómeno, por otro lado, ya antiguo y descrito maravillosamente en la película "West Side Story"); la violencia lúdica asociada en numerosas ocasiones al consumo de drogas y alcohol y la violencia amparada por argumentos políticos -como es el caso del terrorismo callejero, denominado eufemísticamente por los políticos "de baja intensidad", como la tristemente frecuente "Kale borroka" en Euskadi, sin olvidar los dramáticos sucesos del año pasado en Francia con las duras protestas en los barrios musulmanes-. En realidad, son muchas formas de manifestación que tienen un denominador común: la violencia. 
No obstante, las dimensiones del problema entre los jóvenes no parecen evolucionar de forma negativa si nos atenemos a los datos objetivos publicados en el Informe de la Juventud en España 2004, del Ministerio de Asuntos Sociales [2 I], citando como fuente a la Dirección General de Instituciones Penitenciarias. En este informe se concreta que, mientras la población reclusa se ha incrementado y ha pasado de 22.396 internos el 31 de diciembre de 1985, hasta 51.882 el mismo día del año 2002 (sin incluir a Cataluña en esta última cifra), la participación de los jóvenes menores de 25 años ha pasado de 5.652 en 1985 (representando el 25,2\% del total de reclusos) a 6.647 (el $12,8 \%$ del total). Aunque hay que tener en cuenta que a partir del año $200 \mathrm{I}$ la edad penal pasó de 16 a 18 años, en el año 2000, cuando aún la edad penal era de 16 años, la población reclusa menor de 25 años representaba el 14,3\% del total de esa población reclusa. Estos datos nos indican que, al menos entre esas fechas, la población reclusa juvenil tiende a estancarse, mientras que, en general, el número de reclusos aumenta.

\section{4.- CAUSAS Y CIRCUNSTANCIAS QUE ELICITAN ESTAS CONDUCTAS:}

Los delincuentes jóvenes suelen tener una trayectoria previa como agresores en los colegios y antecedentes de familia multiproblemática, independientemente de la clase social, y/o estilos, cuando no trastornos de personalidad principalmente antisocial y narcisista. El ser humano actúa para satisfacer unas necesidades: Ya Maslow [22] a mediados del siglo pasado expuso su teoría sobre la motivación humana $y$, después, otros investigadores han seguido sus pasos y, con algunas variaciones, han dado por válida esa teoría. La historia de la humanidad parece también validar su "pirámide de necesidades", en cuanto es una historia de conductas orientadas a la satisfacción, en primer lugar, de las necesidades fisiológicas (garantizar la comida, el agua y un lugar que proteja de las inclemencias del tiempo); después, de las necesidades de seguridad (protegerse de los ataques de otros); de las necesidades sociales (formar grupos, relacionarse); de las de estima (que los demás le consideren y estimen a uno, o al menos así lo entienda, y que uno tenga una buena autoestima) y, por último, de las necesidades de autorrealización (conseguir la armonía interna entre los objetivos autopropuestos y la conducta). En el intento de satisfacción de estas necesidades, las personas y los grupos han puesto en práctica unas estrategias que desde su perspectiva meditada o espontánea han sido funcionales. En la actualidad, seguimos la misma dirección y creemos que en tanto los seres humanos tengamos las características genéticas y biopsicosociales que tenemos, la seguiremos poniendo en práctica.

Las teorías psicoanalíticas consideran las agresiones como formas de conducta gobernadas por instintos (el thanatos o instinto de destrucción de Freud [23]); la etología por su lado, (K. Lorenz [24], Eibl-Eibesfeldt [25]), postula que se produce una selección natural de los más agresivos como más adaptados para la supervivencia y conservación de la especie; más interés presenta -a nuestros efectos- la teoría de la frustración-agresión $[26,27]$ que insiste en que ante cualquier situación frustrante se genera una tensión, una agresividad que puede tomar distintas formas de manifestación externa.

Pero, los humanos, somos seres abiertos y nuestra conducta está influida, pero no está determinada por nuestros genes. Así, desde la sociobiología [28] se acepta la existencia de una base genética, pero se afirma la influencia de contingencias sociales a las que el sujeto debe aprender a responder de manera agresiva (competición por recursos escasos, encuentros con extraños, etc.) y que la experiencia pueden modificar en grado e intensidad y conducirlas hacia formas violentas o a formas negociadas. 
De este modo, la conducta violenta, como cualquier otra conducta, es el resultado de unos contenidos previos de la persona, tanto biológicos como psicológicos (moldeados a la largo de la historia personal por las experiencias de la interacción social y el aprendizaje social), que se actualizan como una tendencia a manifestarse en interacción con circunstancias situacionales interpretadas por el agente de forma consciente o automática como facilitadoras de la aparición de esa conducta; bien porque se interpreta que uno ha sido provocado por la víctima (agresión reactiva) o, bien, porque es la conducta más adecuada para obtener lo que se desea y uno siente que es competente para llevarla a cabo (agresión instrumental).

Así pues, para entender la conducta violenta nos interesa saber tanto las características personales que se van a actualizar, como las circunstancias psicosociales puntuales elicitadoras de la conducta.

\section{I. Las características personales:}

Los estudios que incluyen resultados sobre el perfil de los agresores suelen concluir que éstos puntúan significativamente más alto en los factores de impulsividad y reactividad [29]; temperamento agresivo e impulsivo [30]; más hiperactividad, conductas disruptivas en las clases y neuroticismo, y menor sensibilidad y un cociente intelectual más bajo [3 I]; más asertivos, fácilmente provocables y a gusto con las agresiones [32]; puntuaciones altas en las escalas de psicoticismo [33]; baja autoimagen, menor competencia académica, y peor conducta y aceptación social [34]

La víctimas, por su parte, se caracterizan por manifestar una tendencia a la huida y falta de asertividad [35]; más tímidas y apocadas, con bajo autoconcepto, mayor inseguridad, sensibilidad y cautela [36]; más introvertidas y con baja autoestima [37]; se perciben como menos competentes que sus compañeros y las chicas, como menos aceptadas socialmente [38]; solos, poco equipados para responder a las agresiones de sus compañeros, con menores habilidades sociales y de comunicación [39]. Las víctimas provocativas manifiestan un perfil de conducta hiperreactivo y emocionalmente inestable [40]. Los que son tanto agresores como víctimas manifiestan un perfil más parecido al de los agresores puros.

La interacción entre los agresores y las víctimas ha sido analizada por algunos autores y las conclusiones a las que han llegado van en la dirección de que la impotencia y el contraataque de las chicas víctimas y el contraataque en los chicos víctimas animaba el comienzo o continuación de la intimidación; en cambio, el no manifestar impotencia por parte de las chicas y el mostrar indiferencia y no contraatacar por parte de los chicos hace que disminuyan las intimidaciones [4I].

\subsection{Las características psicosociales:}

¿Cómo modifica la experiencia la forma de respuesta ante un sentimiento agresivo?. Thorndike [42] en la primera mitad del siglo pasado formuló su famosa "Ley del Efecto" en la que afirma que una conducta recompensada tiende a repetirse y una conducta no recompensada tiende a extinguirse. Pero, según Eysenck [43] las pautas morales del individuo se adquieren por condicionamiento clásico y no se aprenden por la ley del efecto. No obstante, eso no quiere decir que las conductas violentas aprendidas no se repitan o se extingan en función de sus consecuencias. Las conductas violentas le añaden unas características peculiares a las conductas agresivas en cuanto que no son en sí mismas instrumentales para la satisfacción de las necesidades básicas, ya que comportan un exceso de daño gratuito a la víctima y/o pueden ser sustituidas por otras conductas que tienen el efecto instrumental de satisfacer la necesidad a la que responden sin el daño gratuito para la víctima. Estas conductas violentas se ponen en práctica y se repiten en tanto el sujeto siente una 
recompensa y siente que al realizarlas los inconvenientes percibidos son menores que las ventajas percibidas. Aquí está, desde nuestro punto de vista, la clave del mantenimiento de las conductas violentas: que resultan funcionales para quien las realiza. Si no fuese así tenderían a extinguirse. Pero, para que esta afirmación general resulte práctica necesita concretarse en cada caso.

El problema que se plantea ahora es qué hacer para que las conductas agresivas dejen de ser funcionales para quien las realiza. Hay que analizar, primero, la perspectiva del agresor para poder poner en práctica, después, medidas que faciliten su cambio de perspectiva y no le compense ya hacer esas conductas. Para ver cómo decide el agresor realizar una conducta violenta en un momento determinado nos puede servir de guía la teoría de la "acción planificada" de Ajzen y Fishbein [44] y evaluar con el agresor tanto la actitud, como la norma subjetiva y el control percibido de conducta. Según esta teoría, las personas tenemos intención de realizar una conducta en función de la fuerza y sentido de nuestra actitud hacia esa conducta; de la influencia que para nosotros tiene la norma subjetiva; es decir, de lo permeables que seamos hacia lo que creemos que los demás esperan que hagamos en ese momento y del control externo que percibimos que tiene o va a tener esa conducta (recompensas o castigos); una vez que tenemos la intención realizaremos esa conducta si no hay algún control físico que nos lo impida.

Este modelo debería ser completado con el análisis de la fuerza del hábito [45], porque, en una situación concreta, la intención espontánea de poner en marcha una conducta u otra está influenciada por la asociación automática con las conductas realizadas en otras ocasiones similares.

A partir de este análisis podremos comprender el trasfondo de las conductas violentas y delictivas y comprender - asimismo- qué es lo que le sirve de incentivo al agresor o al delincuente para así, en un segundo momento, poner los medios necesarios para que esas conductas dejen de reportarles recompensas. Las consecuencias o anticipación más o menos automática de consecuencias que son percibidas como recompensa suelen ser de tipo psicosocial o psicofisiológica: excepto en las conductas de robo o tráfico de drogas, a través de las cuales se suele obtener una recompensa material, en las conductas de bullying, de violencia contra personas más débiles, delitos sexuales o destrucción de objetos, la recompensa puede estar en: a) la propia descarga de la tensión (agresividad, ira, etc.), b) la satisfacción de sentirse dominante o con poder sobre la víctima, c) la mejora del autoconcepto y de la autoestima a partir de la conformidad de la conducta con la propia escala de valores y de la recompensa social del grupo de pertenencia y/o referencia y, d) la adquisición o mantenimiento de poder y prestigio social en el grupo.

Cualquier conducta violenta conlleva una descarga de una tensión: así que, en primer lugar, para dejar de emitirla, el sujeto debe vivenciar que el bienestar por esa descarga es menor que el malestar de las consecuencias de su conducta. Aquí ya hay un primer obstáculo: las personas valoramos más el placer a corto plazo o las recompensas inmediatas que las postergadas; $y$, por desgracia, el bienestar por la descarga de la tensión es inmediato. El sentirse dominante sobre la víctima puede resultar satisfactorio en tanto cubre la necesidad social de poder cuando hay una carencia en ese sentido $y$, en ese caso, también contribuye a mejorar o mantener en un nivel elevado el autoconcepto y la autoestima; $y$, en función de la escala de valores del grupo, también el poder y prestigio social dentro de su grupo.

\subsection{Las características sociales:}

Las variables sociales que facilitan el aprendizaje y mantenimiento de estas conductas provienen de los distintos niveles de socialización en nuestra cultura: la familia, la escuela, los iguales, los medios de comunicación y la sociedad general [46]. 
La construcción del yo en el ser humano se produce a partir de la interacción con los otros y, sobre todo, con los otros iniciales: por tanto, quienes van a marcar los cimientos de esa construcción es la familia, preferentemente los padres. Como un elemento más del contenido de esa construcción está la interpretación del mundo que éstos tengan, su escala de valores, las actitudes hacia los demás y sus formas de relación. Así pues, los modelos de relación aprendidos en la familia tanto por experiencia directa como vicaria, las escalas de valores y los estilos educativos de los padres llevan a los hijos a la construcción de sus propias escalas de valores y estilos de relación; y, como las personas hacemos una selección perceptiva para defendernos de la disonancia cognitiva y no sentirnos mal, tendemos a elegir de forma más o menos automática aquellos elementos del medio que tienden a confirmar que nuestra perspectiva es válida. Esto lleva a que las interacciones en el marco familiar sean cruciales para la aparición de conductas violentas.

Pero la escuela tiene también una función socializadora. Es cierto que la socialización conlleva, al menos inicialmente, unas dosis de represión de los deseos espontáneos para, en el mejor de los casos, facilitar su racionalización, con lo que se asumiría como deseable esa no puesta en práctica de las conductas que lleven a la satisfacción de esos impulsos y deseos; de este modo, consideramos que es deseable que eso sea así, como un mal menor, en función de una meta superior como es que el bienestar general aumente, que los derechos de los demás sean respetados como queremos que se respeten los nuestros. Pero, al día de hoy, el modelo escolar actual suele ejercer esta función de una forma básicamente frustrante $y$, por tanto, generadora de agresividad... ihay razones suficientes para que a un adolescente le obliguen a estar sentado durante 5 ó 6 horas diarias, callado, oyendo cosas que no le interesan y no quiere oír?.. Estas circunstancias, entre otras tales como la calidad de la relación en clase y la metodología de la enseñanza, son generadoras de frustración y, por tanto, de agresividad (sin entrar en las psicopatologías emergentes) [47, 48]; que el adolescente canalizará de diversas maneras: a) rechazándolas y buscando el bienestar a través de los grupos de iguales, grupos que tienen sus propias normas de socialización - "in-group"- según las cuales el estatus lo consigue cada uno en función de sus "méritos", y no suelen considerar como "meritorio" el respeto a los más débiles o a quienes no pertenecen a su grupo; b) subordinándose al adulto por temor al castigo; c) aceptando emocionalmente las situaciones al entenderlas como buenas porque así lo dicen los adultos "atractivos" y con autoridad referente; o, d) asimilándolas racionalmente porque ven clara la deseabilidad de esas circunstancias y la dificultad de ser sustituidas por otras mejores.

Los iguales suelen ser los referentes más importantes en la segunda década de la vida. La autoestima, que siempre estará abierta a influencias externas, va a ser alimentada por la sensación de ser valorado por los demás; por lo tanto, habrá que hacer lo que es valorado positivamente por ese grupo, lo que le satisface y/o lo que le divierte al grupo [49]... las formas agresivas y violentas de relación social orientadas hacia el exogrupo suelen ser funcionales... hacer bullying, agredir a personas diferentes (percibidas como débiles para facilitar la impunidad), robar, destruir el mobiliario urbano, ingerir alcohol a edades tempranas y/o de forma abusiva, consumir o traficar con drogas ilegales, etc. son conductas que pueden dar prestigio social y aumentar la autoestima.

Desde el marco de la sociedad general, sobre todo a través de los medios de comunica-

ción de masas, se envían mensajes paradójicos a través de la publicidad y de múltiples programas de radio y televisión que, para arañar porcentajes en la cuota de pantalla y audiencia, se orientan a dar carta de normalidad, cuando no de excelencia, a conductas inmaduras y formas agresivas de relación -creando modelos de mala conducta o "contramodelos"- $y$, dado su poder persuasivo, van a ser imitadas por los espectadores u oyentes, principalmente por los menos maduros, y su influencia 
les va a orientar, no ya a un relativismo ético en el que todo vale, sino a la adopción de una escala de valores en la que se encumbra la ley del más fuerte, entiéndase, de quien mejor engaña, de quien tiene menos escrúpulos, de quien se salta las normas con astucia para no ser "pillado", de quien sigue su propio interés despreciando y pasando por encima de los derechos de los demás, del éxito rápido a través del engaño, el abuso o la violencia.

Además, las estructuras sociales propician una cesión de tareas y responsabilidades desde los individuos particulares a la sociedad organizada: así, la educación general y no la formación académica, se piensa que ha de realizarse en las escuelas; la atención a los mayores o a los dependientes, a través de los Servicios Sociales; la previsión de recursos para la vejez le corresponde a la Seguridad Social; la defensa de los derechos y libertades a las Fuerzas de Seguridad; la limpieza de las calles al Ayuntamiento... Esta cesión de tareas y responsabilidades familiares o personales es, sin duda, signo de una sociedad avanzada, pero facilita el riesgo de un grave error con consecuencias muy negativas para la sociedad si no se entiende que esta Sociedad del Bienestar, este "Papá Estado", no tiene que conducir necesariamente a una "infantilización" de los adultos, a un ceder excesivamente las responsabilidades, a atender sólo a los derechos y a obviar las obligaciones correspondientes...

Así pues, los contextos familiar, escolar y social necesitan dar un giro significativo para construir un marco que facilite una socialización de paz, en el que la violencia estructural desaparezca, en el que se eduque a los educadores (los adultos en general, pero principalmente a los padres, profesores y políticos), en el que se facilite la asunción racional y emocional de que es necesario el que a mis derechos les corresponden al mismo nivel mis deberes, y que hay una escala de derechos/obligaciones.

Este giro debe incluir el derecho de la sociedad a defenderse de las "formas bárbaras de relación social" sin caer ella misma en una "respuesta bárbara". Este derecho a defenderse con eficacia conlleva que, en cada caso y de forma ajustada, las consecuencias de los actos violentos recaigan sobre quien los realiza, de tal manera que la relación subjetiva beneficio-coste de esas conductas resulte negativa y, por tanto, disuasoria.

\section{5.- SUGERENCIAS DE PREVENCIÓN:}

A la vista de los antecedentes analizados, el corolario es bien simple: a nuestra sociedad le interesa y urge prevenir la aparición de estas conductas violentas y disminuir sus consecuencias. En este marco, algunas sugerencias prácticas que nosotros apuntamos para su prevención son:

- Poner en práctica "Talleres de preparación para padres" cuyos destinatarios serían las parejas que vayan a tener hijos o adoptarlos. En estos talleres se puede instruir a padres y madres para que faciliten un apego seguro en sus futuros hijos generando así resiliencia $[50,51]$ y facilitando el aprendizaje de interacciones socialmente adecuadas.

- Potenciar programas de formación y asesoramiento para padres desde los ayuntamientos, las asociaciones de vecinos, las AMPAs, etc.

- Mejorar la preparación técnica y psicosocial del profesorado (entrenamiento en habilidades sociales, en gestión de conflictos, mejora de la inteligencia emocional, etc.)

- Mejorar la imagen pública del profesorado y defenderla legalmente -como ya se viene insinuando-.

- Disminuir la ratio profesor/alumno.

- Potenciar la función del tutor.

- Incrementar el número de orientadores en los centros escolares.

- Implementar los medios para que las consecuencias de los actos violentos recaigan sobre 
quienes los realizan y, en ningún caso, sobre las víctimas; de modo que no sean éstas quienes tengan que cambiar de centro escolar.

- Potenciar un código ético para los medios de comunicación de masas e incidir en medidas que hagan eficaces su respeto.

- Incentivar una mayor investigación para analizar las características concretas de estos problemas en cada zona en particular para poner en práctica las medidas pertinentes.

- Adecuar las Leyes y el Código Penal a estas nuevas formas de conducta tan perniciosas y preparar a expertos en Medicina Legal y Forense y en Psicología Forense para poder hacer peritajes y asesorar adecuadamente al respecto.

Como es obvio, éstas son sólo algunas de las posibles medidas a tomar. Su puesta en práctica dependerá de su idoneidad en cada ámbito, de los recursos disponibles y de la voluntad política para implementarlas. Ahora bien, sería ingenuo y utópico el pensar que las conductas violentas van a ser erradicadas a corto o medio plazo o que, simplemente, un endurecimiento penal o leyes "ad hoc" van a hacer que las personas sean más virtuosas, honestas, responsables o pacíficas -la promulgación de la tan cacareada Ley Orgánica de Medidas de Protección Integral de la Violencia de Género, aunque necesaria, ha sido y es un claro ejemplo de esa ingenuidad de muchos "bienpensantes" que creían que con ella estaría resuelto el problema, puesto que los datos demuestran un aumento del número de víctimas cada año-. Pero, y esto no debe olvidarse, tampoco está probado ni creemos que nuestra sociedad actual sea especialmente violenta, en comparación con otras sociedades u otras épocas y momentos históricos; pero -aún así- entendemos que nuestro nivel de desarrollo no debe consentirla y no debe permitir disminuirla, consiguiendo así una mejor calidad de vida para nosotros y para nuestros hijos.

\section{BIBLIOGRAFÍA:}

I.-Real Academia Española. Diccionario de la Lengua Española. Espasa Calpe. Madrid, 2001.

2.-Suárez, M. Mediación. Conducción de disputas, comunicación y técnicas. Paidós. Buenos Aires, 1996.

3.-Ortega, R. y Mora-Merchán, JA. Violencia escolar: mito o realidad. Mergablum Edición y Comunicación. Sevilla,2000.

4.-Oñate, A. y Piñuel, I. Informe Cisneros VII: "Violencia y acoso escolar en alumnos de Primaria, ESO y Bachiller". Instituto de Innovación educativa y Desarrollo directivo. Madrid,2005.

5.-González de Rivera, JL. El maltrato psicológico. Espasa. Madrid,2000.

6.-Gala, FJ. Acoso moral en el ámbito laboral (“mobbing”), en JM. Terradillos y M. Acale (Eds.), Estudios jurídicos sobre siniestralidad laboral. Consejería de Empleo, Junta de Andalucía. Sevilla,2006(pp 53-62).

7.-Gala, FJ. y Lupiani, M. El mobbing como riesgo emergente en la salud laboral, en VV AA, Seguridad, calidad y salud laboral. Consejería de Empleo, Junta de Andalucía. Sevilla,2005(pp II5-I23). 8.-Díaz-Aguado, MJ. La violencia entre iguales en la adolescencia y su prevención desde la escuela. Psicothema,2005. 17(4): 549-558. 9.-Ortega, R. y Mora-Merchán, JA. Op. cit.2000.

10.-Oñate, A. y Piñuel, I. Op. cit.2005.

II.-Loewenstein, LF. Who is the bully?. Bulletin of the British Psychological Society,1978. 31: 316-318.
I2.-Slee, P. Bullyng in the playground: The impact of inter-personal violence on Australian children's perceptions of their play enviroment. Children's Enviroments, 1995.I2 (3): 320-327.

13.-Pereira, B. y Mendoza, D. Facts and figures from the first survey on bullying in Portuguese schools. Actas de la "European Conference on Educational Research". Sevilla,1996(pp 196-197).

I4.-Fonzi, A. y Genta, M. Italy, en P.Smith y K. Morita (Eds), The nature of school bullyng. A cross-national perspective. Routledge. Londres, 1999.

15.-Cerezo, F. y Esteban, M. La dinámica bully-víctima entre escolares. Diferentes enfoques metodológicos. Revista de Psicología Universitaria Tarraconense,1992.14(2):I31-145.

16.-Díaz-Aguado, M., Martínez-Arias, R. y Martín-Seoane, G. Prevención contra la violencia y lucha contra la exclusión desde la adolescencia. Instituto de la Juventud. Madrid,2004.

17.- Iguaz de Miguel, J. Encuesta sobre la convivencia en los centros educativos. Anexos sectoriales. Consejo Escolar de Andalucía de la Consejería de Educación de la Junta de Andalucía. Granada, 2006.

18.- Oñate, A y Piñuel, I. Acoso y violencia escolar en España. Informe Cisneros X. IIEDDI. Madrid, 2007.

19.- Piñuel. I y Oñate, A. AVE: Acoso y violencia escolar. TEA Ediciones. Madrid, 2006.

20.-Ortega, R. y Mora-Merchán, JA. Op. cit.2000. 
21.-López Blasco, A., Cachón, L., Comas, D., Andreu, J., Aguinaga, J. y Navarrete, L. Informe Juventud en España 2004. Instituto de la Juventud. Madrid, 2005.

22.-Maslow, AH. A theory of human motivation. Psychological Review, 1954.50:370-396.

23.-Freud, S. El malestar en la cultura (Obras completas III). Biblioteca Nueva. Madrid, 1968.

24.-Lorenz, K. Sobre la agresión. Siglo XXI. Madrid, 1992.

25.-Eibl-Eibesfeldt, I. Biología del comportamiento humano. Manual de etología humana. Alianza Psicología. Madrid,1993.

26.-Dollard, J., Doob, LW. y Miller, E. Frustration and Agresión. Yale University Press. New Haven, 1939.

27.- Berkowitz, L. Aggressive Humor as a Stimulus to Aggresive Responses. Journal of Presonality and Social Psychology,1970. 16: $710-717$.

28.-Wilson, EP. Sociobiología: La nueva síntesis. Ediciones 0mega. Barcelona, 1980.

29.- Smith, PK. The Silent Nighmare: Bullying and Victimization in School Peer Groups. Comunicación en el Congreso anual de la British Psychological Society. Londres, 1989.

30.-Olweus, D. Bullying at School. What we know and whal we can do. Blackwell. Oxford, 1993.

31.- Loewenstein, LF. Op. cit. 1978.

32.- Stephenson, P. y Smith, D. Bullying in the junior school, en DP. Tattum y DA. Lane (Eds), Bullying in Schools. Trentham Books.Stoke-on-Trent,I989.

33.-Slee, P. y Rigby, K. The relationsship of Eysenck's personality factors and self-steem to b ully/victim behaviour in Autralian school boys. Personality and Individual Difference, 1993.14:37I373.

34.- Austin, S. y Joseph, S. Assessment of bully/victim problems in 8 to II year-olds. British Journal of Educational Psychology, 1996 . 66 (4): 447- 456.

35.- Smith, PK. Op.cit. 1989.

36.- Olweus, D. Op.cit.1993.

37.- Slee, P. y Rigby, K. Op.cit.1993.

38.- Egan, SK.y Perry, DG. Does low self-regard invitevictimization? Developmental Psychology,1998. 34 (2): 299-309.
39.- Loewenstein, LF. The intensive treatment of bullies and victims of bulling in a therapeutic community and school. Education Today, 1994. 44 (4): 62-68.

40.- Schwartz, D.y Dodge, KA. The early socialization of aggressive victims of bulling. Child Development,1997. 68 (4): 665-675.

4I.-Salmivalli, C., Karhunen, J. y Lagerspetz, K. How do the victims respond to bullying?. Aggresive behavior,1996. 22 (2): 99-109.

42.-Thorndike, E. Animal Intelligence. Mc Millan. Nueva York,19II. 43.- Eysenck, HJ. Psicología de la decisión política. Ariel. Barcelona, 1964.

44.- Ajzen, I. y Fishbein, M. Attitudinal and normative variables as predictors of specifics behaviors. Journal of Presonality and Social Psychology,1973. 27: 4I-57.

45.- Triandis, HC. Actitud y cambio de actitud. Toray. Barcelona,1971.

46.-Gómez-Sanabria, A. La adolescencia y la juventud como etapas vulnerables y de transición. Ponencia en el Curso "Trastornos Psicológicos de la Alimentación (anorexia y bulimia). Aspectos clínicos, psicológicos y sociales". Coordinadores F). Gala y M. Lupiani; 58 edición de los Cursos de Verano de la Universidad de Cádiz. Cádiz,2007.

47.-Gala, FJ. y Lupiani, M. Psicopatologías emergentes en la escuela, en M. Lupiani y JA. Moreno, La Salud en el Medio Escolar. Instituto de Estudios Ceutíes. Granada,2007 (pp 285-295).

48.-Lupiani, M y Gala, FJ. Estilos de vida no saludables en la escuela, en M. Lupiani y JA. Moreno, La Salud en el Medio Escolar. Instituto de Estudios Ceutíes. Granada,2007 (pp 275-283).

49.- Sánchez-Bernardos, ML y Quiroga, MC. Autodiscrepancias y relaciones interpersonales en la adolescencia. Psicothema,2004. 16(4), 582-586.

50.-Cyrulnik, B. Los patitos feos. (La resiliencia: una infancia infeliz no determina la vida). Ed. Gedisa. Barcelona,2002.

5I.-Lupiani, M. Nuevos avances y descubrimientos en los factores disposicionales personales predictivos de la felicidad. Ponencia en el Curso "La alegría, el placer y la felicidad: Una aproximación científica a la felicidad". Coordinadores F]. Gala y M. Lupiani; 28 edición de los Cursos de Verano de la Universidad de Cádiz en $S$. Roque. San Roque,2007. 